\title{
Automated Autonomous Vehicles: Prospects and Impacts on Society
}

\author{
Tschangho John Kim ${ }^{1,2}$ \\ ${ }^{1}$ Urban and Regional Systems, University of Illinois at Urbana-Champaign, Urbana and Champaign, USA \\ ${ }^{2}$ Sid and Reva Dewberry Department of Civil, Environmental, and Infrastructure Engineering, \\ George Mason University, Fairfax, USA \\ Email: tjohnkim@gmail.com
}

How to cite this paper: Kim, T.J. (2018) Automated Autonomous Vehicles: Prospects and Impacts on Society. Journal of Transportation Technologies, 8, 137-150. https://doi.org/10.4236/jtts.2018.83008

Received: December 28, 2017

Accepted: May 4, 2018

Published: May 7, 2018

Copyright (c) 2018 by author and Scientific Research Publishing Inc. This work is licensed under the Creative Commons Attribution International License (CC BY 4.0).

http://creativecommons.org/licenses/by/4.0/

\begin{abstract}
All automobile manufacturing companies, Google and Microsoft have announced recently their production of the Fully Automated Autonomous Vehicles (FAAVs), otherwise known as driverless cars. A few FAAVs would be available in the market as early as in 2018, but mostly in 2020's. When FAAVs will be available to and become affordable by the average consumers, the implications to the society would be far reaching. The purpose of the paper is to examine the prospect of the popularity of FAAVs and their socio-economic implications to the future society of the World. The paper examines potential impacts on selected sectors of the society including changes in demand for automobiles, its impact on the use of oil, on the environment, and on urban land uses, to list a few.
\end{abstract}

\section{Keywords}

Automated Autonomous Vehicles, Development of Transport Technology, Battery Resources and Technology, Impacts on Electricity Demand, Socio-Economic Impacts, Impacts on Oil Industry, Implications to Urban Land Uses

\section{Introduction}

New technologies have altered the physical possibilities of human settlement, as well as the economic, cultural, and political relations of human activities. Certainly, transportation technologies such as highways, railroads, electric streetcars, and automobiles have transformed the human settlement space tremendously [1]. Transportation has become an integrated and necessary part of urban life, and today's urban dwellers use various types of transportation modes to 
keep the urban environment habitable and comfortable [2]. Introduction of internal combustion engines, multi-speed transmissions, better steering, electric motors, cruise control, and emission control technologies are a few examples of automobile technologies that have affected people's welfare which, in turn, led to successive and dramatic reorganizations of the urban areas in the past century in the World.

"Petrol cars will vanish in 8 years" was the title of an article published in the Australian Financial Review on May 15, 2017 [3]. The article was based on a report by a private think tank, RethinkX which published under the title, "Rethinking Transportation 2020-2030" [4]. The report claimed that vehicles equipped with gasoline fueled internal combustion engine (ICE) will be gradually replaced by electric cars and, particularly by fully automated autonomous vehicles (FAAVs) ${ }^{1}$, otherwise known as driverless cars or self-driving cars, in the near future. In fact, the majority of car manufacturers have announced their plans to produce electric cars and FAAVs, some as early as by 2018 and the rest by 2020 s [5].

Soon after the report by the RethinkX was published, automaker Volvo announced on July 5, 2017 that its entire lineup will either become electric or hybridized by 2019 [6]. On July 6, 2017, France government's Ecology Minister Nicolas Hulot announced to end the sale of gasoline and diesel vehicles by 2040 [7] and become carbon neutral 10 years later, citing of the Volvo plans and mentioning India's plan targeting an all-electric vehicles fleet by 2030 [8]. On July 26, British government announced that new diesel and petrol cars will be banned from UK roads by 2040 [9].

In light of these developments, the purpose of this article is to shed light on the life cycles of the ICE cars and FAAVs by closely examining the validity of assumptions behind claims made by the RethinkX and to assess the socio-economic implications to the future society of the World.

The major claims reported in the report by the RethinkX include:

1) Fully automated autonomous vehicles (FAAVs) will be available and all regulations regarding the use of FAAVs will be approved by 2020 in the USA.

2) Vehicle fleet size will drop by over $80 \%$ due to the popular use of FAAVs, from 247 million vehicles in $2020^{2}$ to 44 million by 2030 in USA. Consequently, supply for cars and truck will be reduced by $70 \%$.

3) At the same time, passenger miles driven in 2030 will increase to 6 trillion miles from 4 trillion miles in 2015 due to the increase use of FAAVs and $95 \%$ of passenger miles in 2030 will be driven by FAAVs with all kind of services provided by the market using FAAVs.

4) Annual manufacturing of new ICE mainstream cars sold to individuals will drop to zero by 2030 .

5) Demand for oil will drop to 70 million barrels per day (mbd) in 2030, down

${ }^{1}$ See Appendix for different levels of autonomous car.

${ }^{2}$ The total number of registered cars in the USA is 270 million and the report by RethinkX does not explain the reason behind the reduction of fleet size from 2017 to 2020 by 33 million cars. 
from the peak of $100 \mathrm{mbd}$ in 2020 and the price of oil will fall to around $\$ 25$ per barrel.

6) Lower volumes of demand and prices of oil will have geopolitical implications for energy security, military spending and regional stability.

In the sections that follows, the long-term development trend of the surface transportation will be briefly reviewed to shed light on the life cycles of transportation technologies which, in turn, could allude to the prospect of FAAVs in the coming years.

\section{Long-Term Development Trend for Surface Transportation Technologies}

Many cars are already equipped with cameras and sensors to help drivers avoid potential accidents. Now, competition is developing not only between traditional automakers such as GM, Volvo and Hyundai, but also among technology companies like Apple and Google as they plan to place FAAVs on the street as early as 2020 .

The advent of app-enabled car services such as Uber which have upended the traditional taxi business model by swiftly matching riders with drivers based on proximity and need. The services offer clean, owner-operated vehicles and convenient pickup arrangements at competitive prices, usually with little or no wait time, even during peak ridership hours. What else could be the most disruptive technology other than a ubiquitous driverless "TaaS" 3 service in the future! The advent of the fully automated autonomous vehicles (FAAVs) will certainly enable to provide such services in the near future.

The search for and development of cheaper and better surface transportation modes have been evolved rapidly in the past and eventually make them commercially available sometime in the future, if not in 2020s. Despite some unreasonable assumptions and unsubstantiated claims reported in the RethinkX, it is inevitable that the technology trends for the development of the surface transportation modes in the past 150 years will continue and they teach us a good deal of lessons as shown in Figure 1.

The horse-drawn omnibus was overtaken by cable cars in 1870s, which, in turn, was over taken by electric tramways around 1910; the later was replaced by bus in 1930s and then by automobiles as they became economical and technologically superior. In fact, the new transportation mode replaced the existing one when the new mode became technologically superior and economically competitive to the existing ones.

Thus, it seems to be inevitable that the new technology based FAAVs and its related services will eventually replace the existing ICE cars when the cost of owning and/or operating them becomes economical [10]. The time might not in next 8 years, but would be soon in the near future when FAAV become affordable to the average consumers.

3“TaaS" is acronym for Transportation-as a-Service, the term the RethinkX used in its report to refer to such services as Uber without drivers. 


\section{Life Cycles of Surface Transportation Modes in USA}

1980 to 1948 show the year for the peak ridership for each mode

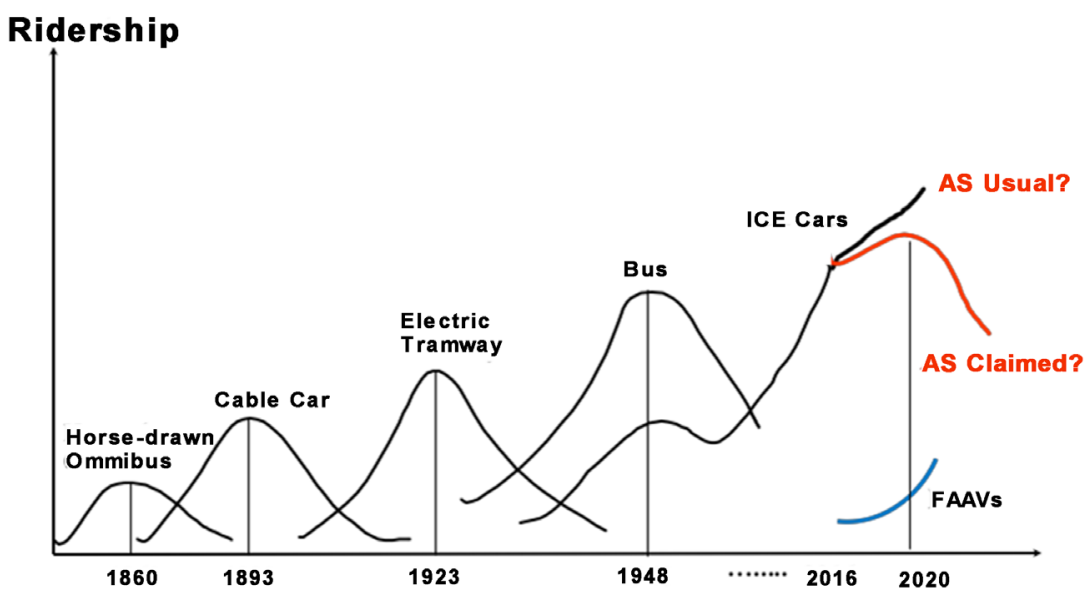

Figure 1. Life cycle of surface transportation mode in USA. Source: Various data assembled by the author.

\section{Advancement of Fully Automatic Autonomous Vehicles}

\subsection{Production and Operational Plans}

As reported earlier, almost all automobile manufacturing companies and other IT companies have announced their plans to produce FAAVs in the near future. To list a few, Volkswagen plans to introduce FAAVs by 2019, Audi by 2020, Ford by 2020, GM by 2020 or sooner, Nissan by 2020, Hyundai and Kia by 2020 , BMW by 2021, Toyoda by 2020, Jaguar and Land-Rover by 2024, and Daimler Benz by 2025 .

A real-world test site called K-City is under construction for evaluating performances of FAAVs before placing them into the market by the Ministry of Land, Infrastructure \& Transport of South Korea. The facility will be an area of approximately 90 acres with a budget of approximately USD 10 million. The K-City will be a test site for performance of FAAVs, providing self-driving data. The data obtained there constitute valuable big data that can be utilized for car insurance, urban planning and many more as well as self-driving car developments. The data from this testing ground could also shed lights on an optimal combination of communications, software and mobility services.

\subsection{Advancement of Battery Technology}

High costs of lithium-ion battery cells have been one of the main hindrances to large-scale electric-car adoption, as they typically lead to higher purchase prices for electric cars than comparable internal-combustion models. However, due to improved chemistry, manufacturing processes, and economies of scale, average electric-car battery costs continue to decline as we have experienced from the development cycles of all technologies in the past.

"Battery pack prices are expected to halve to $\$ 215$ per kilowatt hour by 2020 from $\$ 400 / \mathrm{kWh}$ now... the industry would need a global battery production ca- 
pacity of 600 gigawatt hours, enough to build 8.6 million cars with an average battery size of $70 \mathrm{kWh}$ " [11]. (Research and Market July 2-17). Desjardin (2017) reported that "for the foreseeable future, the improvement of battery technology relies on modifications being made to already-existing lithium-ion technology. In fact, experts estimate that lithium-ions will continue to increase capacity by $6 \%-7 \%$ annually for a number of years" [12] Recently, researchers at the University of Texas, Austin developed the first all-solid-state battery cells that could lead to safer, faster-charging, longer-lasting rechargeable batteries for handheld mobile devices, electric cars and stationary energy storage [13].

Among currently available electric cars, the ranges for a few less expensive electric vehicles include 238 miles for the $\$ 37,495$ Chevy Bolt, 115 miles for the $\$ 30,000$ Ford Focus Electric, and 107 miles for the \$31,545 Nissan Leaf. Tesla's own forthcoming Model 3 has promised a 215 mile-range at a price of $\$ 35,000$ in all prices before incentives. The Tesla's Model S 100D, currently listed at a base price of $\$ 92,500$, offers an EPA-rated range of 335 miles on a full charge, making it the longest-range consumer electric vehicle in the world today [14].

\subsection{Does the World Have Enough Lithium?}

Among various components that make FAAVs operable, one critical requirement is lithium-ion battery, and among many components required for lithium-ion batteries, the key element is lithium itself. Lithium is the lightest solid element and an excellent conductor of electricity and heat. If there would be 44 million FAAVs by 2030 in the USA as the researchers of the RethinkX predicted and if a Lithium-ion battery uses between 3 to $4 \mathrm{~kg}$ of Lithium as Gruber et al. [15] estimated, then total amount lithium needed to make 44 million batteries by 2030 amounts to 176,000 tons.

Lithium is being used for various industrial productions. The estimated global end use of lithium as of 2016 in the order of high usage were: Batteries (39\%), Ceramics \& glass (30\%), Lubricating greases (8\%), Continuous casting (5\%), Polymers (5\%), Air treatment (4\%), Aluminum Production (1\%), Pharmaceutical (1\%), Others (8\%) [16]. Figure 2 shows lithium resources and reserves world-wide.

Table 1 shows the global total of 36, 000 tons of lithium produced by various countries in the world in 2016 . There are about 10 countries in the world where lithium deposits were found as shown in Figure 2. The concentration of lithium reserves is in South America, where there's approximately 66\% of the world's reserves, particularly in Argentina, Bolivia and Chile. Mohr et al. [17] published a detailed assessment of global lithium supply and demand. However, the total amounts of lithium deposits known as of today are not conclusive. While 39 million tons of in-situ lithium resources are known to be available, the actual recoverable lithium will likely be about 19 Million tons as reported earlier in [15].

Even if there would be only 44 million FAAVs operating by 2030 as the study by the RethinkX estimated in the USA and even if up to $90 \%$ of lithium could be recycled from batteries after 10 years of operation, the scarcity of lithium 


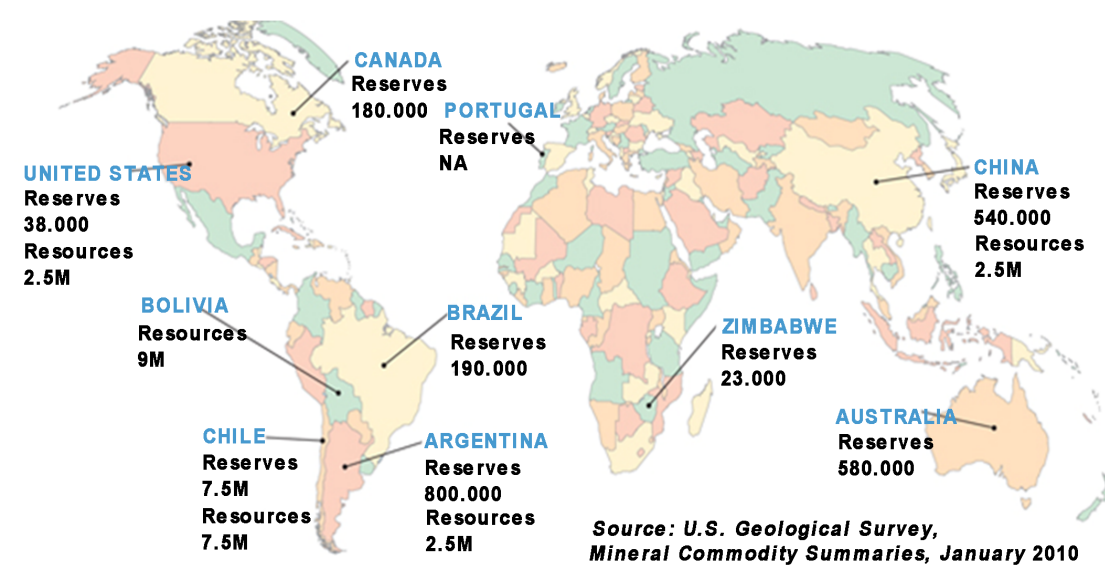

Figure 2. World Lithium Resources and Reserves in Tons. Source: Gruber, Paul W., Pablo A. Medina, Gregory A. Keoleian, Stephen E. Kesler, Mark P. Everson, and Timothy J. Wallington, 2011, "Global Lithium Availability: A Constraint for Electric Vehicles?", Journal of Industrial Ecology, 15: 5, 760-775.

Table 1. List of countries by lithium production in 2016 .

\begin{tabular}{ccc}
\hline Rank & Country & Production (tons) \\
\hline 1 & Australia & 36,000 \\
2 & Chile & 14,300 \\
3 & Argentina & 5700 \\
4 & China & 2000 \\
5 & Zimbabwe & 900 \\
6 & Portugal & 200 \\
7 & Brazil & 200 \\
& World & 59,300 \\
\hline
\end{tabular}

deposits would ignite a fierce competition for searching for and securing them among countries producing FAAVs and lithium-ion batteries, unless alternatives to lithium-ion batteries would be developed.

Recently, Benson et al. [18] reported that large quantities of lithium are thought to be hiding in lake deposits right in the caldera of super-volcanoes such as Yellowstone.

\section{Impact Assessment of FAAVs on the Society}

The advent of FAAVs and their related industry would have severe geopolitical implications for energy security, military spending and regional stability. Among many others, the followings seem to be more relevant to the transportation engineers and planners.

\subsection{Demand for Automobiles}

The authors claimed that automobiles will be dropped from 270 million in 2017 in the USA to 247 million in 2020 and to 44 million in 2030. The authors' esti- 
mation of the $80 \%$ of fleet size reduction was based on an assumption that the price of FAAV become competitive to the conventional ICE cars and the majority of consumers would purchase an FAAV or choose the mode, "Transportation-as a-Service (TaaS)," the term the RethinkX used in its report to refer to such services as Uber without drivers.

I am not convinced that the number of automobiles will be so drastically dropped due to the advancement of technology and the use of FAAVs. Global sales volume of cars has been constantly increased. In 2016, it was 88.1 million, up $4.8 \%$ from a year ago. In USA, it was 18 million in 2016 , increased from 17.5 million a year ago. In 2017, the total number of registered cars in the USA is 270 million owned by 120 million households, i.e. each household owns average 2.25 cars. This trend indicates that the cars that have been purchased by consumers in recent years and in years to come may still be on the road for some time in the future.

Even if FAAVs will be fully commercialized and became affordable, and the TaaS services became available to average consumers, it would be very unlikely that consumers will abandon all ICE cars they purchased in recent years and in next few years. If and when the fully commercialize services such as "TaaS" may become available, the average household would still keep at least one car for the use of family, and the car will most likely be an ICE car. That may amount to 120 million cars, even assuming the total number of household in 2017 would be constant. The difference between 120 million and 44 million is too big to be realized by 2030. Thus, the estimate of the car fleet size and consequent reduction of the consumption of oil will have to be carefully scrutinized and studied.

\subsection{Demand for Oil}

Oil remains the world's leading fuel, accounting for $33 \%$ of global energy consumption. Roughly $63 \%$ of oil consumption is from the transport sector in the world. For 2017, the IEA Oil Market Report [19] forecasted that the average demand for the year worldwide would reach more than 98 million barrels of oil per day, equivalent to 35.8 billion barrels a year.

In 2016, the United States consumed a total of 7.19 billion barrels of petroleum products, an average of about 19.63 million barrels per day, one fifth of the global demand [20]. Of the total petroleum consumption, $71 \%$ was used by the transportation sector and the remaining $29 \%$ by other sectors; $23 \%$ by the industry, $5 \%$ by the commercial and residential sectors, and $1 \%$ for electric power generation.

Borrowing the claims by the authors of the RethinkX that the US peak demand for oil being $20 \mathrm{mbd}$, and assume that transportation sector used $71 \%$ of oil consumption as was in 2016, demand for oil for the transportation sector would be $14.2 \mathrm{mbd}$. Further assuming that 2.25 cars per household would be reduced as 1.0 ICE car (44\% reduction) as speculated above, it means $6.25 \mathrm{mbd}$ will be for the transportation sector. Thus, the total oil consumption be $12 \mathrm{mbd}$ in 2030, $6.25 \mathrm{mbd}$ for the transport sector and $5.8 \mathrm{mbd}$ for other sectors, assum- 
ing that demand for electricity by all sectors except transportation remains constant. On the other hand, the demand for oil for generating electricity would be increased from $1 \%$ since FAAVs use batteries since the nuclear power plants may be faced out gradually.

\subsection{Demand for Electricity}

In 2016, about 4.08 million gigawatts per hour (gWh) of electricity were generated at utility-scale facilities in the United States. The US Energy Information Agency (EIA) reported that "about $65 \%$ of this electricity generation was from fossil fuels (coal, natural gas, petroleum, and other gases), about $20 \%$ was from nuclear energy, and about 15\% was from renewable energy sources" in 2016 [21]. The U.S. EIA estimates that an additional 19,000 gWh of electricity generation was from small-scale solar photovoltaic systems in 2016.

To install an average battery size of $70 \mathrm{kWh}$ for 44 million FAAVs by 2030, for example, the industry would need an additional 3080 gWh per day for charging 44 million batteries, assuming one battery per FAAV charging once a day. To generate the required amount electricity, about 33 more nuclear power plants of the size of the Palo Verde nuclear power plant in Arizona will be needed with full capacity operating for 24 hours a day. The Palo Verde plant is the largest combined electricity generating capacity in the USA with 3937 megawatts generation capacity [22]. Or another hydroelectric power plant equivalent to the Hoover Dam size will have to be constructed.

Some may cast hope that the development of hydrogen cars would reduce dependence on electricity. Even hydrogen cars, however, need electricity for producing hydrogen for operation. As of 2017, there are 3 hydrogen cars publicly available in the markets; the Toyota Mirai, the Hyundai ix35 FCEV, and the Honda Clarity. The two key reasons why manufacturers of cars focus on electric motors and not on hydrogen engines are the high cost of producing hydrogen and the low efficiency. The price for $1 \mathrm{~kg}$ of $\mathrm{H}_{2}$ is about 3 times that of 1 gallon of gasoline and the well-to-wheel efficiency for hydrogen is known to be less than $25 \%$ [23]. In 2016, less than $5 \%$ of hydrogen in the USA is produced by electrolysis using electricity and water, consuming approximately $50-80 \mathrm{kWh}$ of electricity to produce one kilogram of $\mathrm{H}_{2}$, equivalent to about $40 \mathrm{kWh}$ of electric energy [24].

\subsection{On the Environment}

US EPA reported that "twenty-six percent of U.S. greenhouse gas (GHG) emissions is from transportation. Transportation is the second leading source of GHG emissions in the United States, just behind electricity" [25]. Electric cars are known to be green and thus no pollutants will be emitted from them. Cities' air will be cleaner. However, all depends on where the electricity comes from. About two billion metric tons of $\mathrm{CO}_{2}$ per year coming from smokestacks from coal-fired power plants, the single-largest source of greenhouse gas pollution in the U.S. Biello (2016) reported that "...electric cars may or may not help the country combat climate change", as long as coals are used for generating elec- 
tricity [26].

\subsection{On Land Use}

American Automobile Association (AAA) reported in 2016 that Americans use cars average 2 hours per day [27], pointing that cars are parked for 22 hours per day. Assuming that the US population would reach to 359 million as the US Census Bureau estimated [28], the number of households would be about 120 million. Further assuming that average household would have only one car due to the popularity of FAAVs, the total parking spaces would be reduced by $40 \%$, from 270 million lots in 2017 to 110 million lots, a size equivalent to the state of Rhode Island could be converted to other uses.

Ben-Joseph (2015) reported that, in most urban areas in the USA, land uses for parking "cover more than one-third of the metropolitan footprint" [29]. Chester et al. (2015) estimated that $14 \%$ of Los Angeles is currently used for parking [30]. According to the 2010 U.S. Census Bureau, the Los Angeles metropolitan area has a total area of 4850 square miles and $14 \%$ of the land would be 679 square miles. Reduction of $40 \%$ of the LA metropolitan area' sparking spaces due to the popular use of FAAVs would be about 270 square miles, an area similar to Lexington, KY.

The implications to urban land uses would be unprecedented (Kim, 2015) [31], if $40 \%$ of parking space would be released in an urban area. What impacts to LA would be, if an area size equivalent to 270 square miles could be released from parking space to be used to other urban activities?

\subsection{On Congestion}

Reduction of fleet of cars will undoubtedly ease the level of congestion. How much would it be and what impacts would it bring to the socio-economic changes are not yet carefully studied. Without accompanying a detailed analysis, Frey [32] asserted the followings:

- For a city of 2 million people, a fleet of 30,000 autonomous vehicles will displace $50 \%$ of peak commuter traffic.

- During off-peak times, 30,000 autonomous vehicles will handle virtually all other transportation needs.

- Less than 4 million autonomous cars will replace $50 \%$ of all commuter traffic in the U.S.

- With roughly 250 million people in the U.S. living in urban communities, 3.75 million autonomous vehicles will handle $50 \%$ of peak commuter traffic in the country.

- That means 4 million autonomous vehicles will replace our need for half of all cars, or roughly 129 million vehicles.

\subsection{On Other Impacts}

It is still too early to predict who is most likely to benefit from the use of FAAVs, manufacturers or operators. Uber's profits could very likely increase with the 
cost of the driver eliminated, and car-sharing services like Zipcar could reduce or even eliminate the need to own a vehicle. This may reduce auto sales by more than a million units annually over the next decade as the researchers of the RethinkX predicted.

Frey (2017) further claimed few of other possible impacts as follows:

- Noise levels in cities will be cut in half.

- The shift to electric vehicles will dramatically change the sound of a city.

- Cities will lose over $50 \%$ of their revenue by the reduction of sales tax and reduced income from traffic violations, gas tax, vehicle licensing, parking meters, and parking garages.

\section{Summary and Conclusion}

While the estimations and claims by the authors of the Rethinking Transportation 2020-2030 seem to be a bit exaggerated, it is inevitable that the technology trends for the development of the surface transportation modes in the past 150 years will continue and it tells us a good deal of lessons as shown in the Figure 1. The new mode of transportation will overtake the existing mode in the market when the new one is technologically superior and economically cheaper.

Thus, the new technology based FAAV and its related on-demand transportation services such as driverless Uber-like businesses will eventually replace the existing ICE vehicles and businesses provided by passenger services driven by drivers when the cost of owning and/or operating FAAVs becomes economical. Thus, the time of replacement of ICE, when happens, will depend on the cost of the new mode. The time might not in next 8 years, but would be in years to come in the near future when FAAV become affordable to the average consumers.

When FAAV becomes affordable and FAAV based on-demand transport services become ubiquitously available, consumers might not need to own more than one carper household since driverless mobility services would become attractive. Cost for providing driverless transport services will become affordable for average consumers since the portion of the labor cost will be eliminated. About $50 \%$ of the current Uber charges are labor cost [33]. Assuming one car per household in the future and the total number of households in the USA will be constant as in 2017, the total number of cars would be around 120 million.

Assuming even the half of 120 million cars would be FAAVs or electric cars, demand for electricity for charging 60 million batteries daily would be surmountable. Even to charge batteries daily for 44 million FAAVs as claimed by the authors of the Rethinking Transportation 2020-2030, the additional demand for electricity would be equivalent to the amount of electricity generated by the Hoover Dam.

Demand for lithium for batteries would surge as FAAVs become popular. Even if up to $90 \%$ of lithium could be recycled from batteries after 10 years of operation, the scarcity of lithium deposits would ignite a fierce competition for 
searching for and securing them among countries producing FAAVs and lithium-ion batteries.

The popular use of FAAVs will undoubtedly affect oil prices. However, the use of oil for electricity generations could surge and thus possible changes of the global demand for oil, and their implications to the future life styles, and the global economy are yet to be carefully studied.

The advent of affordable FAAVs will have tremendous implications to the socio-economic environment in the future world: the environment, land use in urban areas, traffic and congestion, and the way the mobility industries work, to list a few.

\section{References}

[1] Kim, T.J., Claus, M., Rank, J.S. and Xiao, Y. (2009) Technology and Cities: Processes of Technology-Land Substitution in the 20th Century. Journal of Urban Technolo$g y, 16,63-88$.

[2] Kim, T.J. (2011) Urban Space with Instant and Ubiquitous Access Technologies. Journal of Transportation Technologies, 1, 1-3.

[3] Evans-Pritchard, A. (2017) Petrol Cars Will Vanish in 8 Years, Says US Report from Stanford Economist. Financial Review, Fairfax Media Limited, Sydney.

[4] Arbib, J. and Seba, T. (2017) Rethinking Transportation 2020-2030. A RethinkX Sector Disruption Report.

https://static1.squarespace.com/static/585c3439be65942f022bbf9b/t/591a2e4be6f2e1 c13df930c5/1494888038959/RethinkX+Report_051517.pdf

[5] Inventivio GmbH (2017) Driverless Car Market Watch: Forecast. http://www.driverless-future.com/?page_id=384

[6] Ewing. J. (2017) Volvo, Betting on Electric, Moves to Phase Out Conventional Engines. The New York Times.

https://www.nytimes.com/2017/07/05/business/energy-environment/volvo-hybrid-e lectric-car.html

[7] Chrisafis, A. and Vaughan, A. (2017) France to Ban Sales of Petrol and Diesel Cars by 2040 . The Guardian.

https://www.theguardian.com/business/2017/jul/06/france-ban-petrol-diesel-cars-2 040-emmanuel-macron-volvo

[8] Wattles, J. (2017) India to Sell Only Electric Cars by 2030. CNNTech. http://money.cnn.com/2017/06/03/technology/future/india-electric-cars/index.html

[9] Asthana, A. and Taylor, M. (2017) Britain to Ban Sale of All Diesel and Petrol Cars and Vans from 2040. The Guardian.

https://www.theguardian.com/politics/2017/jul/25/britain-to-ban-sale-of-all-dieseland-petrol-cars-and-vans-from-2040

[10] Kim, T.J. (2002) Transportation Planning and Engineering. In: Knowledge forsustainable Development-An Insight into the Encyclopedia of Life SupportSystems, EOLSS Publishers/UNESCO, Paris, France, Oxford, UK. http://www.eolss.net

[11] Research and Market (2017) EV Batteries and Materials: Technology, Trends, and Market Forecasts.

https://www.researchandmarkets.com/reports/4033389/ev-batteries-and-materials-t egy-trends?gclid=Cj0KEQjw7pHLBRDqs-X8hZ3Mgp0BEiQAXIo9rqm7pRWEry3q 0nIaMiSVVRCV_SBmQ4j5g1Gq2z8fNU4aApiO8P8HAQ 
[12] Desjardins, J. (2017) The Future of Battery Technology. Visual Capitalist. http://www.visualcapitalist.com/future-battery-technology/

[13] Braga, M.H., Grundish, N.S., Murchisona, A.J. and Goodenough, J.B. (2017) Alternative Strategy for a Safe Rechargeable Battery. Energy and Environmental Science, 10, 331-336.

[14] Morris, D.Z. (2017) Tesla Quietly Introduces Longest-Range Electric Car on the Market. The Fortune Magazine, 22 January 2017.

[15] Gruber, P.W., Medina, P.A., Keoleian, G.A., Kesler, S.E., Everson, M.P. and Wallington, T.J. (2011) Global Lithium Availability: A Constraint for Electric Vehicles? Journal of Industrial Ecology, 15, 760-775. https://doi.org/10.1111/j.1530-9290.2011.00359.x

[16] US Geological Survey (2017) Mineral Commodity Summaries 2017. 100 p. https://minerals.usgs.gov/minerals/pubs/mcs/2017/mcs2017.pdf

[17] Mohr, S.H., Mudd, G.M. and Giurco, D. (2012) Lithium Resources and Production: Critical Assessment and Global Projections. Minerals, 2, 65-84. http://www.mdpi.com/2075-163X/2/1/65/htm

[18] Benson, T.R., Coble, M.A., Rytuba, J.J., Gail, A. and Mahood, G.A. (2017) Lithium Enrichment in Intracontinental Rhyolite Magmas Leads to Li Deposits in Caldera Basins. Nature Communications, 8, Article No. 270. https://doi.org/10.1038/s41467-017-00234-y

[19] International Energy Agency (2017) Oil Market Report. https://www.iea.org/oilmarketreport/omrpublic/

[20] U.S. Energy Information Administration (2017) How Much Oil Is Consumed in the United States? https://www.eia.gov/tools/faqs/faq.php?id=33\&t=6

[21] U.S. Energy Information Agency (2017) What Is US Electricity Generation by Energy Source? https://www.eia.gov/tools/faqs/faq.php?id=427\&t=3

[22] U.S. Energy Information Agency (2017) How Much Electricity Does a Nuclear Power Plant Generate? https://www.eia.gov/tools/faqs/faq.php?id=104\&t=3

[23] Bossel, U. (2006) Does a Hydrogen Economy Make Sense? Proceedings of the IEEE, 94, 1826-1837. https://doi.org/10.1109/JPROC.2006.883715

[24] Wikipedia (2017) Who Killed the Electric Car? https://en.wikipedia.org/wiki/Who_Killed_the_Electric_Car\%3F

[25] USEPA (2017) Transportation and Climate Change. https://www.epa.gov/air-pollution-transportation/carbon-pollution-transportation

[26] Biello, D. (2016) Electric Cars Are Not Necessarily Clean. Scientific America, 11 May 2016. https://www.scientificamerican.com/article/electric-cars-are-not-necessarily-clean/

[27] Johnson, T. (2016) Americans Spend an Average of 17,600 Minutes Driving Each Year. AAA.

http://newsroom.aaa.com/2016/09/americans-spend-average-17600-minutes-drivin g-year/

[28] Colby, S.L. and Ortman, J.O. (2015) Current Population Reports. US Census Bureau.

https://www.census.gov/content/dam/Census/library/publications/2015/demo/p251143.pdf

[29] Ben-Joseph, E. (2015) Rethinking a Lot: The Design and Culture of Parking. MIT Press, Cambridge, MA. 
[30] Chester, M., Fraser, A., Matute, J., Flower, C. and Pendyala, R. (2015) Parking Infrastructure: A Constraint on or Opportunity for Urban Redevelopment? A Study of Los Angeles County Parking Supply and Growth. Journal of the American Planning Association, 81, 268-286. http://www.tandfonline.com/author/Pendyala\%2C+Ram https://doi.org/10.1080/01944363.2015.1092879

[31] Kim, T.J. (2015) Framework for Spatial Models for Future Cities. In: Nijkamp, P., Rose, A. and Kourtit, K., Eds., Regional Science Matters, Springer, Dordrecht, 353-372. https://doi.org/10.1007/978-3-319-07305-7_17

[32] Frey, T. (2017) 25 Shocking Predictions about the Coming Driverless Car Era in the U.S.

http://www.futuristspeaker.com/job-opportunities/25-shocking-predictions-about-t he-coming-driverless-car-era-in-the-u-s/

[33] Wile, R. (2017) Here's How Much Uber Drivers Really Make.

http://time.com/money/4845407/uber-drivers-really-make-per-hour/ 


\section{Appendix}

Level of Autonomous for Electric Cars

Level 0 . All major systems are controlled by humans as almost all currently operating cars are.

Level 1. Certain systems such as cruise control and automatic braking maybe controlled by the car, one at a time.

Level 2. Able to accelerate and steering, but requires humans for safe operation.

Level 3. Able to manage safety-critical functions generally, but driver takes over when alerted.

Level 4. Fully autonomous in some driving scenarios, but not all.

Level 5. Completely capable of self-driving in any circumstances. 